\section{Observation and modeling of a historic African dust intrusion into the Caribbean Basin and the southern \\ U.S. in June 2020}

\author{
HONGBIN YU ${ }^{1}$, QIAN TAN ${ }^{2,3}$, LILLIAN ZHOU ${ }^{4}$, YAPING \\ ZHOU $^{4,5}$, HUISHENG BIAN ${ }^{4,5}$, MIAN CHIN $^{4}$, CLAIRE L \\ RYDER $^{6}$, ROBERT C LEVY ${ }^{4}$, YASWANT PRADHAN ${ }^{7}$, \\ YINGXI SHI ${ }^{4,5}$, QIANQIAN SONG ${ }^{8}, \mathrm{ZHIBO} \mathrm{ZHANG}^{8}$, \\ PETER COLARCO ${ }^{4}$, DONGCHUL $\mathrm{KIM}^{4,9}$, LORRAINE A \\ REMER $^{5}$, TIANLE YUAN ${ }^{4,5}$, OLGA MAYOL-BRACERO ${ }^{10}$ \\ AND BRENT N HOLBEN ${ }^{4}$
}

${ }^{1}$ NASA Goddard Space Flight Center

${ }^{2}$ BAERI

${ }^{3}$ NASA Ames

${ }^{4} \mathrm{NASA}$ GSFC

${ }^{5} \mathrm{UMBC} / \mathrm{JCET}$

${ }^{6}$ University of Reading

${ }^{7}$ Met Office

${ }^{8} \mathrm{UMBC}$

${ }^{9}$ USRA

${ }^{10}$ University of Puerto Rico

Presenting Author: hongbin.yu@nasa.gov

A massive African dust plume intruded into the Caribbean Basin and the southern U.S. in late June 2020, which was nicknamed the "Godzilla" dust plume. The MODIS data record registered this intrusion as a historic event over the past two decades. The plume caused hazardous air quality in Puerto Rico and significantly degraded air quality in the southern U.S., particularly in the Florida Panhandle and Texas. In this study we used CALIOP, MODIS, and SEVIRI remote sensing observations to characterize the evolution of the dust plume and evaluate the GEOS model simulations. The dust plume, originating from the convectively generated haboobs over sources in West Africa, was lifted from the desert surface to altitudes of up to 6-8 $\mathrm{km}$. Due to the persistence of a closed atmospheric circulation system over West Africa, the large but not extreme daily dust loading from Sahara accumulated in the African coast for about four days. This led to a peak AOD of 3.5 in the African coast and then the record-breaking African dust intrusion into the Caribbean. The dust plume travels westward at an average speed of $1000 \mathrm{~km} \mathrm{~d}^{-1}$ and descends at a rate of about $500 \mathrm{~m} \mathrm{~d}^{-1}$. In comparison to satellite observations, the GEOS model well reproduced the MODIS observed tracks of the meandering dust plume. However, the model substantially underestimated dust emissions from haboobs and did not lift up enough dust to the middle troposphere for ensuing long-range transport, possibly related to the model's coarse resolutions. Consequently, the model largely missed the CALIOP observed elevated dust plume along the cross-ocean track and underestimated the dust intrusion into the Caribbean by a factor of 4. Given the substantial differences in the dust vertical distribution between GEOS and CALIOP, assimilating MODIS AOD would put too much of the dust in the lower layers, artificially enhance the dust deposition along the transport path, and introduce high bias in the surface dust concentration. Modeling improvements need to focus on developing more realistic representations of moist convection, haboobs, and the vertical transport of dust. 